\title{
Specific and non-specific resistance to aminoglycosides in Escherichia coli
}

\author{
S. L. MAWER ${ }^{1}$ AND D. GREENWOOD
}

From the Department of Microbiology and Public Health Laboratory, City and Sherwood Hospitals, Hucknall Road, Nottingham NG5 IPH, UK

SUMMARY The turbidimetric responses of a strain of Escherichia coli K12 to gentamicin and tobramycin were investigated. Both agents showed antibacterial activity below the conventionally measured minimum inhibitory concentration, but exposure to such subinhibitory concentrations of either agent generated a bacterial population which was able to grow in previously inhibitory concentrations at a rate equivalent to that of the parent culture. The increase in resistance was nonspecific in that both aminoglycosides were equally affected, and was unstable on multiple passage in drug-free broth.

The response to tobramycin was unaffected by the presence of an $\mathbf{R}$ factor conferring gentamicin resistance, but exposure of the $\mathrm{R}$ factor bearing strain to gentamicin caused a concomitant increase in the resistance to tobramycin, apparently by a non-specific adaptive mechanism similar to that observed with the parent strain. It is suggested that prior treatment of a gentamicin-resistant organism with gentamicin (as may occur during blind therapy) may adversely affect the subsequent response to other aminoglycosides.

Gentamicin is now widely used as the treatment of choice for many serious Gram-negative infections. Tobramycin has a similar spectrum of activity to gentamicin (Benveniste and Davies, 1973; Andrews et al., 1973) but is unaffected by some of the bacterial enzymes which inactivate gentamicin. The difference between an adequate therapeutic dosage and toxic dosage of these drugs is small, especially in patients with renal failure (Noone et al., 1974; Mawer et al., 1974). It is therefore desirable that the most efficient way of using them be established.

To gain a better understanding of the interaction between drug and bacterium we have investigated the response of a strain of Escherichia coli $\mathrm{K} 12$ to various concentrations of gentamicin and tobramycin by continuous turbidimetric monitoring and have attempted to assess the effect of possession of an $R$ factor conferring resistance to gentamicin alone on the responses to gentamicin and tobramycin.

\section{Material and methods}

Escherichia coli $\mathrm{K} 12$ strain $\mathrm{J} 53\left(\mathrm{~F}^{-}\right.$, pro $^{-}$, met ${ }^{-}$;

1Present address: Public Health Laboratory, Northern General Hospital, Herries Road, Sheffield S5 7AU, UK Received for publication 27 June 1977
Clowes and Hayes, 1968) and a derivative of this strain, J53 (RS28) carrying the R factor RS28, were kindly provided by Dr Naomi Datta.

The R factor RS 28 was originally derived from a strain of Serratia marcescens and belongs to the compatibility group $\mathbf{M}$, which has an unusually wide host range (Hedges et al., 1975). RS28 confers resistance to ampicillin, streptomycin, tetracycline, chloramphenicol, and gentamicin.

Growth medium was the 'complete' medium of Greenwood and O'Grady (1973) modified by replacing the phosphate buffer by tris (hydroxymethyl) aminomethane (TRIS) in order to avoid interference with aminoglycoside activity by phosphates. The medium (CMT broth) has the following constituents per litre: glucose $5 \mathrm{~g}$, casitone pancreatic digest (Difco) $10 \mathrm{~g}$, yeast extract (Difco) $5 \mathrm{~g}, \mathrm{NaCl}$ $5 \mathrm{~g}$, TRIS buffer $6 \mathrm{~g}$ adjusted to $\mathrm{pH} 7 \cdot 2$ with $\mathrm{HCl}$.

Gentamicin was obtained from British Schering Ltd, and tobramycin from Eli Lilly \& Co Ltd, both as pure powders. Stock solutions were prepared in sterile distilled water from which appropriate working dilutions were made.

Minimum inhibitory concentrations (MICs) of gentamicin and tobramycin for the test strains were estimated by a conventional tube dilution method using CMT broth. 
Continuous turbidimetric measurements were obtained using the 12-channel opacity monitoring system described by Mackintosh et al. (1973). Six tubes containing $19 \mathrm{ml}$ of CMT broth and $1 \mathrm{ml}$ of an appropriate dilution of antibiotic or sterile distilled water (drug-free control) were seeded from an overnight broth culture to achieve an inoculum of $\mathrm{ca} 10^{6}$ organisms per $\mathrm{ml}$. At the end of each experiment subcultures onto solid media were made to check that growth in antibiotic was not due to contamination. Adaptation was studied by seeding a fresh series of antibiotic-containing tubes with bacteria growing in the presence of peri-MIC concentrations of antibiotic in a previous experiment.

The stability of induced resistance was tested by serial daily subculture of adapted strains in antibiotic-free CMT broth, the turbidimetric response to graded antibiotic concentrations being investigated after $1,7,12,18$, and 24 subcultures.

\section{Results}

The MICs of gentamicin and tobramycin for $E$. coli $\mathrm{K} 12 \mathrm{~J} 53$ were 4 and $2 \mu \mathrm{g}$ per $\mathrm{ml}$ and for J53 (RS28) were 32 and $4 \mu \mathrm{g}$ per $\mathrm{ml}$, respectively.

RESPONSE OF E. coli K12 J53

Continuous turbidimetric records of $E$. coli $\mathrm{K} 12 \mathrm{~J} 53$ grown in the presence of gentamicin and tobramycin are shown in Fig. 1a and b.

In the presence of $0.25 \mu \mathrm{g}$ gentamicin per ml or 0.5 $\mu \mathrm{g}$ tobramycin per $\mathrm{ml}$ the growth curve closely followed that of the control. In the presence of $0.5 \mu \mathrm{g}$
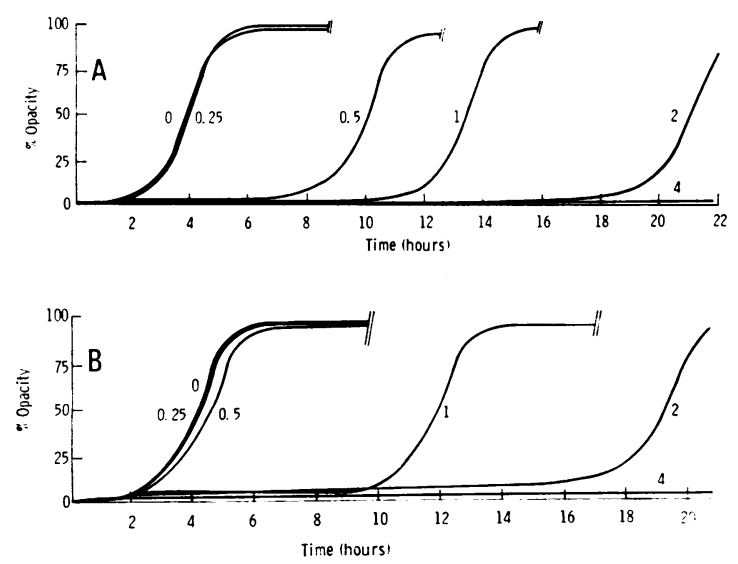

Fig. 1 Continuous opacity records of E. coli $K 12 \mathrm{~J} 53$ in the presence of various concentrations ( $\mu \mathrm{g} \mathrm{per} \mathrm{ml}$ ) of (A) gentamicin, and $(B)$ tobramycin. gentamicin per $\mathrm{ml}(\mathrm{MIC} / 8)$ or $1 \mu \mathrm{g}$ tobramycin per $\mathrm{ml}(\mathrm{MIC} / 2)$ growth was suppressed for a time, although once growth occurred, the slope of the curve was the same as for the drug-free control. Thus the minimum antibacterial concentration (MAC), the lowest concentration of antibiotic achieving an observable antibacterial effect in this system, was 0.5 $\mu \mathrm{g}$ gentamicin per $\mathrm{ml}$ and $1 \mu \mathrm{g}$ tobramycin per $\mathrm{ml}$. As the concentration of antibiotic was further increased, the time taken for growth to attain a level of $50 \%$ of maximum opacity $\left(\mathrm{T}_{50}\right)$ increased correspondingly until a concentration (corresponding to the MIC) was reached at which growth was suppressed for the 22-hour period of observation. Subcultures onto solid media showed that delayed growth was not due to contamination, although the colonies of the previously suppressed cultures were much more variable in size and shape than those of the original strain.

\section{ADAPTATION TO INCREASED RESISTANCE}

The culture which grew in $2 \mu \mathrm{g}$ gentamicin per $\mathrm{ml}$ $\left(T_{50}=21 \mathrm{~h}\right.$, Fig. 1a) was used as the inoculum for a fresh series of gentamicin-containing CMT broths. In broth containing $2 \mu \mathrm{g}$ gentamicin per $\mathrm{ml}$ (that is, the concentration to which the culture had previously been exposed) this culture grew as rapidly as it and its parent $\mathrm{J} 53$ did in antibiotic-free medium $\left(\mathrm{T}_{50}=\right.$ $3.8 \mathrm{~h}$ ) (Fig. 2). Gentamicin, $4 \mu \mathrm{g}$ per $\mathrm{ml}$ (the MIC of the original strain), delayed the growth of this culture $\left(\mathrm{T}_{50}=6 \mathrm{~h}\right)$ and higher concentrations $(\geqslant 8 \mu \mathrm{g} / \mathrm{ml})$ suppressed growth for the 22-hour period of observation. Thus by a single passage in gentamicin the MAC increased to equal the original MIC, an eight-fold increase. By this means a culture was derived which grew in $4 \mu \mathrm{g}$ gentamicin per $\mathrm{ml}$ but at a reduced growth rate $\left(T_{50}=7 \cdot 3 \mathrm{~h}\right)$.

Further adaptation could be slowly achieved by serial passage in increasing concentrations of antibiotic. The ability to grow in increasing concentra-

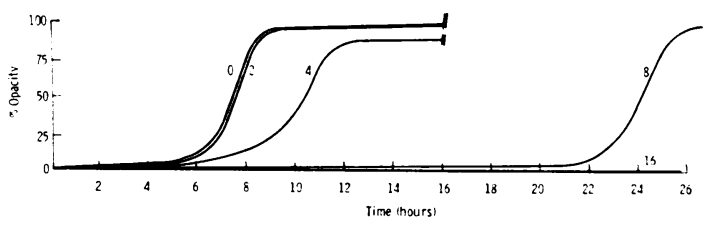

Fig. 2 Continuous opacity records of E. coli K12 J53 in the presence of various concentrations $(\mu \mathrm{g} \mathrm{per} \mathrm{ml})$ of gentamicin. The inoculum was derived from a culture growing in $4 \mu \mathrm{g}$ gentamicin per $\mathrm{ml}$ in a previous experiment. 
tions of gentamicin was accompanied by increasingly irregular colonial morphology on solid media. Virtually identical results were obtained using tobramycin.

CROSS RESISTANCE OF ADAPTED STRAINS The strain of $E$. coli $\mathrm{K} 12 \mathrm{~J} 53$ adapted to grow in $4 \mu \mathrm{g}$ gentamicin per $\mathrm{ml}$ was also tested against tobramycin and an identical response was observed, the MAC now equalling the original MIC for tobramycin.

STABILITY OF ADAPTIVE RESISTANCE

The strain of $E$. coli $\mathrm{K} 12 \mathrm{~J} 53$ adapted to grow in $4 \mu \mathrm{g}$ gentamicin per $\mathrm{ml}$ was serially passaged through antibiotic-free CMT broth. An immediate reversion to greater susceptibility to gentamicin was not found. However, a slow progression towards greater susceptibility was observed, but the process of reversion was not quite complete even after 24 passages (Figs. 1a, 2, and 3).

EFFECT OF R FACTOR RS 28

\section{Turbidimetric response}

The rate of growth of J53 (RS28) in antibiotic-free broth was the same as that of its parent, J53. In the presence of $2 \mu \mathrm{g}$ gentamicin per ml J53 (RS28) grew uninterruptedly, but with each increase in concentra-

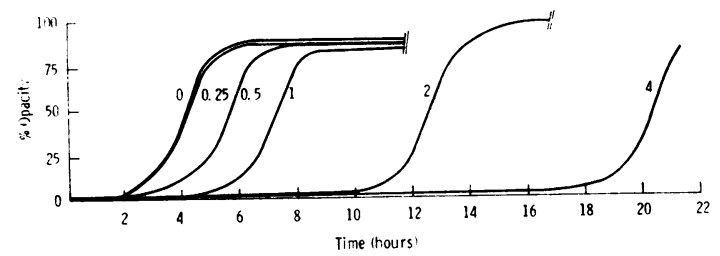

Fig. 3 Continuous opacity records of E. coli K12 J53 in the presence of various concentrations ( $\mu \mathrm{g} \mathrm{per} \mathrm{ml}$ ) of gentamicin. The inoculum was the same culture as that used in the experiment shown in Fig. 2 after 24 daily passages in antibiotic-free broth.



Fig. 4 Continuous opacity records of E. coli $K 12 J 53$ $R S 28$ in the presence of various concentrations ( $\mu g$ per ml) of gentamicin. tion above the MAC, $4 \mu \mathrm{g}$ gentamicin per $\mathrm{ml}$, there was an increase in the time taken for the cultures to reach $50 \%$ opacity $\left(T_{50}\right)$ (Fig. 4$)$. This pattern of response to different concentrations of gentamicin was similar to that shown by the parent J53 to eightfold lower concentrations of gentamicin. The MIC of gentamicin for J53 (RS28) was greater than $32 \mu \mathrm{g}$ per $\mathrm{ml}$. However, the possession of the $\mathrm{R}$ factor appeared to have little effect upon the sensitivity to tobramycin; the MAC was $0.5 \mu \mathrm{g}$ per $\mathrm{ml}$, and the MIC remained unchanged.

\section{Adaptation to increased resistance}

Cultures of J53 (RS28) growing after initial suppression of growth showed a similar pattern of adaptation to that observed with the parent strain J53. The MAC of a culture initially suppressed by 32 $\mu \mathrm{g}$ gentamicin per ml, but growing in this concentration during the overnight incubation period, increased to $64 \mu \mathrm{g}$ gentamicin per $\mathrm{ml}$, and the MIC to $>128 \mu \mathrm{g}$ gentamicin per ml. Furthermore, the increased resistance to gentamicin was reflected in a concomitant increase in resistance to tobramycin, the MAC and MIC being raised to 4 and $8 \mu \mathrm{g}$ tobramycin per $\mathrm{ml}$, respectively.

\section{Discussion}

Although the measurement of MIC and MBC values is generally regarded as the definitive test of the in vitro activity of antimicrobial agents, many factors may influence the results obtained. For aminoglycosides the result may be affected by various components of the medium, its $\mathrm{pH}$, and the method of performing the test. What is not generally recognised is that the conventionally determined tube dilution MIC value represents a measurement taken at an arbitrary point in time during a continuing series of events. Continuous turbidimetric monitoring of cultures exposed to aminoglycosides as they would be in a conventional tube dilution test clearly shows this. An eight-fold difference in MIC was observed between a reading taken after six hours' incubation, when the control tube was fully grown, and one taken after 24 hours' incubation (Fig. 1a). Which of these results is the correct one in clinical terms is a matter of speculation, but as the MIC end-point appears to be controlled by the ability of the culture to adapt to otherwise inhibitory concentrations of the drug, the MAC is at least likely to be more reproducible and less affected by the density of the bacterial inoculum.

Bacteria growing at concentrations of antibiotic between the MAC as defined above and MIC as measured by a conventional tube dilution technique form a very small proportion of the original bacterial 
population (Waterworth, 1972), but under the selective pressure of antibiotic levels approaching the MIC they quickly become the majority population. In the present study $E$. coli $\mathrm{K} 12 \mathrm{~J} 53$ was easily trained to grow in concentrations of gentamicin and tobramycin close to those to which bacteria may be exposed in vivo for a large part of conventional therapeutic regimes. Although peak serum levels may exceed the level of adaptation which is easily achieved, such levels are attained only transiently. It is generally believed that strains adapted to resistance in this way are unimportant clinically owing to loss of virulence. Weinstein et al. (1971) demonstrated loss of virulence for mice in strains of Pseudomonas aeruginosa which had been adapted to quite high gentamicin levels. However, at this level of adaptation these strains exhibited (a phenomenon that we confirm) grossly abnormal growth characteristics. Continuous turbidimetric monitoring of $E$. coli $\mathrm{K} 12$ $\mathrm{J} 53$ showed that no measurable change in the rate of growth, as measured by the ability to achieve a $50 \%$ opacity level $\left(T_{50}\right)$, occurred at low levels of adaptation with this organism and that slightly increased resistance was not a severe handicap since after 24 subcultures in antibiotic-free broth a population adapted to a moderate increase in resistance had not completely returned to its original fully sensitive state. An important feature of this type of resistance is that it appears to extend to other aminoglycosides (Houang and Greenwood, 1977). It is possible that those 'coliforms' frequently isolated from superficial lesions which have a decreased sensitivity to all aminoglycosides are partially adapted strains.

The effects of an R factor (RS28) conferring resistance to gentamicin but not to tobramycin by the production of an inactivating enzyme are different from those produced by adaptation (Figs 4 and 2). In this case delayed growth in concentrations of gentamicin that are initially inhibitory may simply reflect the time taken for the gentamicin to be enzymically inactivated. However, re-exposure of the emergent bacterial population to gentamicin revealed that adaptation was contributing to the overall effect. Furthermore, the sensitivity to tobramycin was also substantially decreased by previous exposure to gentamicin, although possession of the $\mathbf{R}$ factor did not itself affect the intrinsic susceptibility of the organism to tobramycin.

The demonstration that exposure of a gentamicinresistant organism to gentamicin can also decrease the susceptibility of the organism to another aminoglycoside suggests that blind therapy with one aminoglycoside may compromise the success of subsequent treatment with another, even if the infecting organism proves to be resistant to the first drug by an enzymic mechanism which does not affect the second. If these in vitro considerations are substantiated clinically, it may be that blind therapy with aminoglycosides might have to be used more circumspectly than it is at present, at least in those centres where gentamicin resistance is a problem.

This work formed part of a project undertaken by one of us (SLM) during a course of study leading to the degree of MSc in Medical Microbiology, University of London. We are indebted to Dr N. Datta for kindly providing the cultures of $E$. coli $\mathrm{K} 12$ $\mathrm{J} 53$ used in these experiments.

\section{References}

Andrews, J., Williams, J. D., and Geddes, A. M. (1973). Bacteriological studies with tobramycin. Proceedings of the 8th International Congress of Chemotherapy, Athens, 1973, pp. 5-11.

Benveniste, R., and Davies, J. (1973). Mechanisms of antibiotic resistance in bacteria. Annual Review of Biochemistry, 42, 471-506.

Clowes, R. C., and Hayes, W., eds (1968). Experiments in Microbial Genetics. Blackwell Scientific Publications, Oxford and Edinburgh.

Greenwood, D., and O'Grady, F. (1973). Comparison of the responses of Escherichia coli and Proteus mirabilis to seven $\beta$-lactam antibiotics. Journal of Infectious Diseases, 128, 211-222.

Hedges, R. W., Rodriguez-Lemoine, V., and Datta, N. (1975). R Factors from Serratia marcescens. Journal of General Microbiology, 86, 88-92.

Houang, E., and Greenwood, D. (1977). Aminoglycoside cross-resistance patterns of gentamicin-resistant bacteria. Journal of Clinical Pathology, 30, 738-744.

Mackintosh, I. P., O'Grady, F., Greenwood, D., Watson, B. W., Crichton, T. C., Piper, R., and Ferrer, A. (1973). A twelve channel bacterial growth monitoring system. Biomedical Engineering, 8, 514-515 and 526.

Mawer, G. E., Ahmad, R., Dobbs, S. M., McGough, J. G., Lucas, S. B., and Tooth, J. A. (1974). Prescribing aids for gentamicin. British Journal of Clinical Pharmacology, 1, 45-50.

Noone, P., Parsons, T. M. C., Pattison, J. R., Slack, R. C. B., Garfield-Davies, D., and Hughes, K. (1974). Experience in monitoring gentamicin therapy during treatment of serious Gram-negative sepsis. British Medical Journal, 1, 477-481.

Waterworth, P. M. (1972). The in vitro activity of tobramycin compared with that of other aminoglycosides. Journal of Clinical Pathology, 25, 979-983.

Weinstein, M. J., Drube, C. G., Moss, E. L. Jr., and Waitz, J. A. (1971). Microbiologic studies related to bacterial resistance to gentamicin. Journal of Infectious Diseases, 124, Supplement, 11-17. 